\title{
Metastatic basal cell carcinoma - A dramatic case
}

\author{
Gavin David French MD, David D Jewer MD FRCSC \\ Department of Surgery, Health Sciences Centre, St John's, Newfoundland
}

\begin{abstract}
GD French, DD Jewer. Metastatic basal cell carcinoma - A dramatic case. Can J Plast Surg 2000;8(5):199-203.
Metastatic basal cell carcinoma (MBCC) is extremely rare, with an incidence of $0.0028 \%$ to $0.1 \%$. Typical lesions are large, ulcerated, neglected, refractory to treatment and occur more commonly in middle-aged men. Metastases are usually single and to local lymph nodes. Multiple metastases to distant sites are much less common. Certain criteria must be met to diagnose MBCC. A case of MBCC meeting the criteria for diagnosis is reported. The present case is unusual in that the patient is a young woman and the tumour metastasized diffusely throughout the skeleton.
\end{abstract}

Key Words: Basal cell; Carcinoma; Metastatic

\section{Carcinome basocellulaire métastatique - Un cas dramatique}

RÉSUMÉ : Le carcinome basocellulaire métastatique est extrêmement rare, son incidence se situant entre 0,0028 \% et 0,1\%. En général, les lésions sont grandes, ulcérées, négligées, réfractaires au traitement et surviennent plus fréquemment chez les hommes d'âge moyen. Les métastases sont habituellement isolées et affectent les ganglions lymphatiques. La présence de métastases multiples affectant des sites distants est beaucoup moins fréquente. Certains critères doivent s'observer pour que l'on puisse poser le diagnostic de carcinome basocellulaire métastatique. On présente ici un cas qui répond aux critères diagnostiques. Ce cas est inhabituel du fait qu'il s'agit d'une patiente jeune et que la tumeur a produit des métastases diffuses dans tout le squelette.

$\mathrm{C}$ utaneous malignancies are the most common neoplasm in humans. Basal cell carcinoma (BCC) accounts for approximately $75 \%$ to $80 \%$ of these cases and is the most common malignant disease (1). BCC occurs predominantly in the head and neck region (85\%) of white people (99\%) between the ages of 40 and 79 years $(95 \%)$, and is more common in men than in women $(2,3)$.

Despite the high prevalence of BCC, metastases are very rare. In 1951, Lattes and Kessler (4) defined the following, now well accepted, criteria for the diagnosis of metastatic BCC (MBCC).

The primary tumour must be in the skin and not the mucosa.

Metastasis must be documented at a site distant from the primary tumour and not the result of direct extension.

Histological analysis must reveal the metastasis and primary tumour to be similar in subtype and consistent

with BCC without a squamous component.

Prevalence rates have ranged from $0.0028 \%$ in a group of Australian dermatology patients (5) to $0.1 \%$ in an American surgical centre (6). The typical primary tumour is large, ulcerated, recurrent and locally aggressive $(7,8)$.

A dramatic case of $\mathrm{BCC}$, which was initially recurrent and subsequently widely metastatic, is reported. A brief review of the literature is also presented with a focus on the relation of this case to the usual profile of an MBCC.

\section{CASE PRESENTATION}

In February 1991, a 28-year-old woman with a large skin lesion was incidentally discovered in a rural area by a visiting public health nurse. Subsequent evaluation by a local family practitioner revealed a painless, ulcerative, foul-smelling lesion $7 \mathrm{~cm}$ in diameter with a well-demarcated border on the right side of the patient's forehead. The lesion had been

Correspondence and reprints: Dr David D Jewer, Room 1842, Health Sciences Centre, Prince Phillip Drive, St John's, Newfoundland A1B 3 V6.

Telephone 709-737-6437,fax 709-737-6295, e-mail djewer@morgan.ucs.mun.ca 
slowly growing for approximately seven years and had started at the site of a partial thickness burn from a curling iron. She had never seen a physician, had a grade 10 education and lived on social assistance.

The patient was referred to a tertiary hospital where laboratory investigations revealed only anemia (hemoglobin $96 \mathrm{~g} / \mathrm{L}$, mean cell volume $68 \mathrm{fL}$, serum ferritin $3.1 \mathrm{~g} / \mathrm{L}$ ), and lesion cultures grew Staphylococcus aureus. Biopsy of the lesion showed $\mathrm{BCC}$ of the keratotic type, invasive to at least the level of the muscle. Skull radiographs showed lucent areas in the outer table of the right side of the frontal bone with the inner table appearing to be intact. Computed tomography (CT) scan of the skull and brain revealed involvement of both the inner and outer tables of the right side of the frontal bone. Chest x-ray revealed no abnormalities. A technetium bone scan showed a $10 \mathrm{~cm}$ diameter of increased uptake in the right frontal region with no other skeletal abnormalities.

In March 1991, skin and muscle were surgically excised with a $2 \mathrm{~cm}$ margin. The frontotemporal bone was excised and a $2 \mathrm{~mm}$ thick tumour was discovered in the epidural space. This tumour was removed by blunt dissection and electrocautery without dissection of the dura. The original plan was to do an immediate cranioplasty, but because of the epidural tumour, scalp rotation flap and skin grafting were done and followed with adjuvant radiotherapy. Analysis of surgical specimens revealed typical BCC showing an adenoid and morpheaform pattern with some pleomorphic areas. Some keratinizing areas were seen but only in the context of BCC. The patient's postoperative course was complicated by an area of skin necrosis that was regrafted. She received 4650 cGy of radiation in 18 fractions to the right side of the frontal skull in May 1991. Her course was without further complication, and nine months later in February 1992, a cranioplasty was done.

In January 1993 (two years after her initial presentation), the patient was seen with a one-month history of left-sided facial swelling. The swelling was not associated with any pain, headache or visual disturbances. Examination revealed obvious swelling of the left side of the face with two small lumps in the midline over the frontal bone. CT scan showed destruction of both the inner and outer tables in the left fronto/parasaggital region, and technetium bone scan showed areas of increased uptake in the same region. The patient was taken to the operating room, and a craniotomy was done to remove a large bony defect and revealed galeal involvement. The tumour was $1 \mathrm{~cm}$ thick in the epidural space, and after excision, the defect was closed with split-thickness skin graft. Pathology reports showed BCC in the removed skin and bone that was similar in appearance to the original tumour. Magnetic resonance imaging was performed in February to assess the potential benefit of adjuvant radiotherapy. Magnetic resonance imaging revealed areas of enhancement in the left frontal and right parietal region that could not be differentiated as signs of the recent surgery or recurrent tumour. Adjacent brain tissue was seen to be uninvolved. It was decided that the tumour had recurred and was probably incurable, but a trial of radiation to the whole scalp, skull and dura
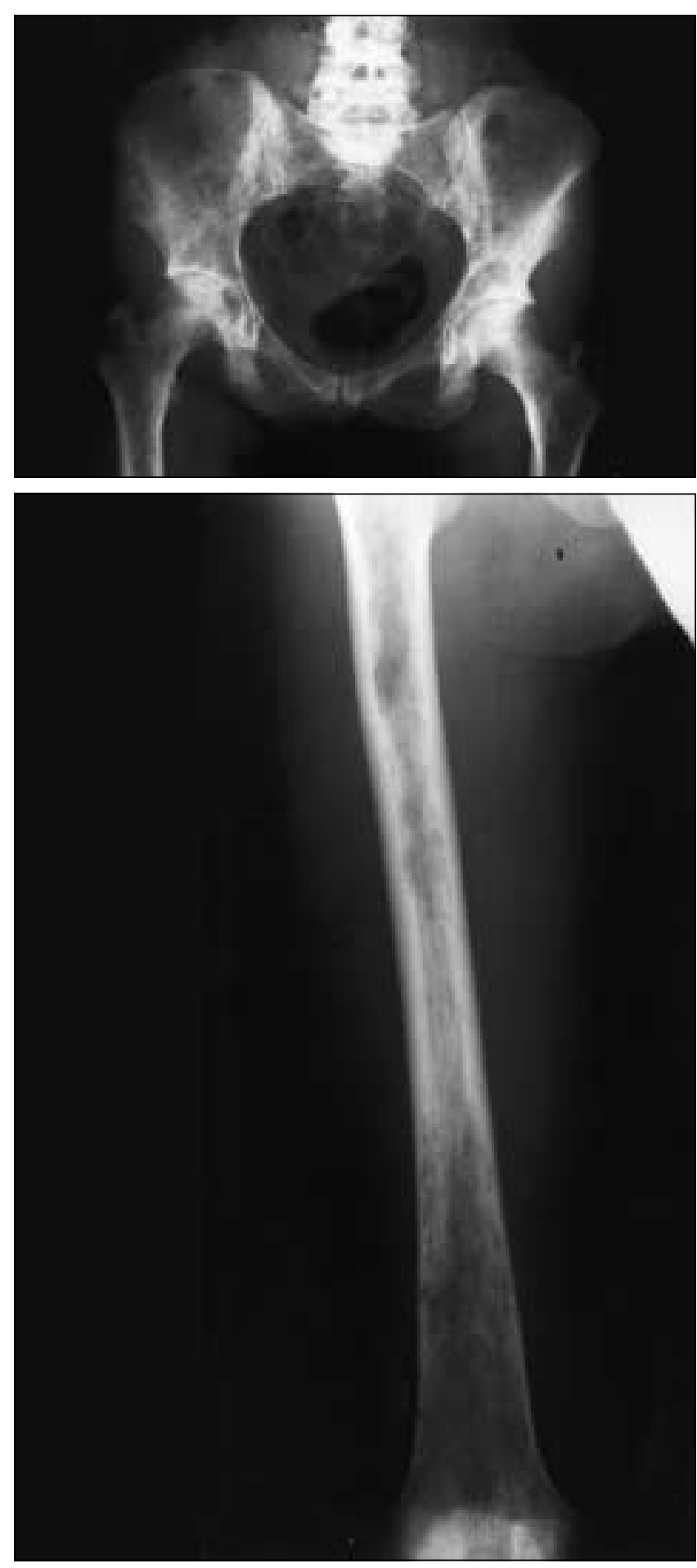

Figure 1) X-ray of the pelvis (top) and right femur (bottom) showing diffuse metastatic basal cell carcinoma revealing an obvious mottled appearance and numerous lytic areas within the bone

was considered. She then received $2000 \mathrm{cGy}$ to the right and left lateral brain.

The patient was followed in a clinic for approximately one year, and then in January 1994, she was readmitted to hospital for management of an infected cranioplasty. Swabs from her wound grew Saureus, and her anemia was persistent. She was in hospital approximately three months; during that time 

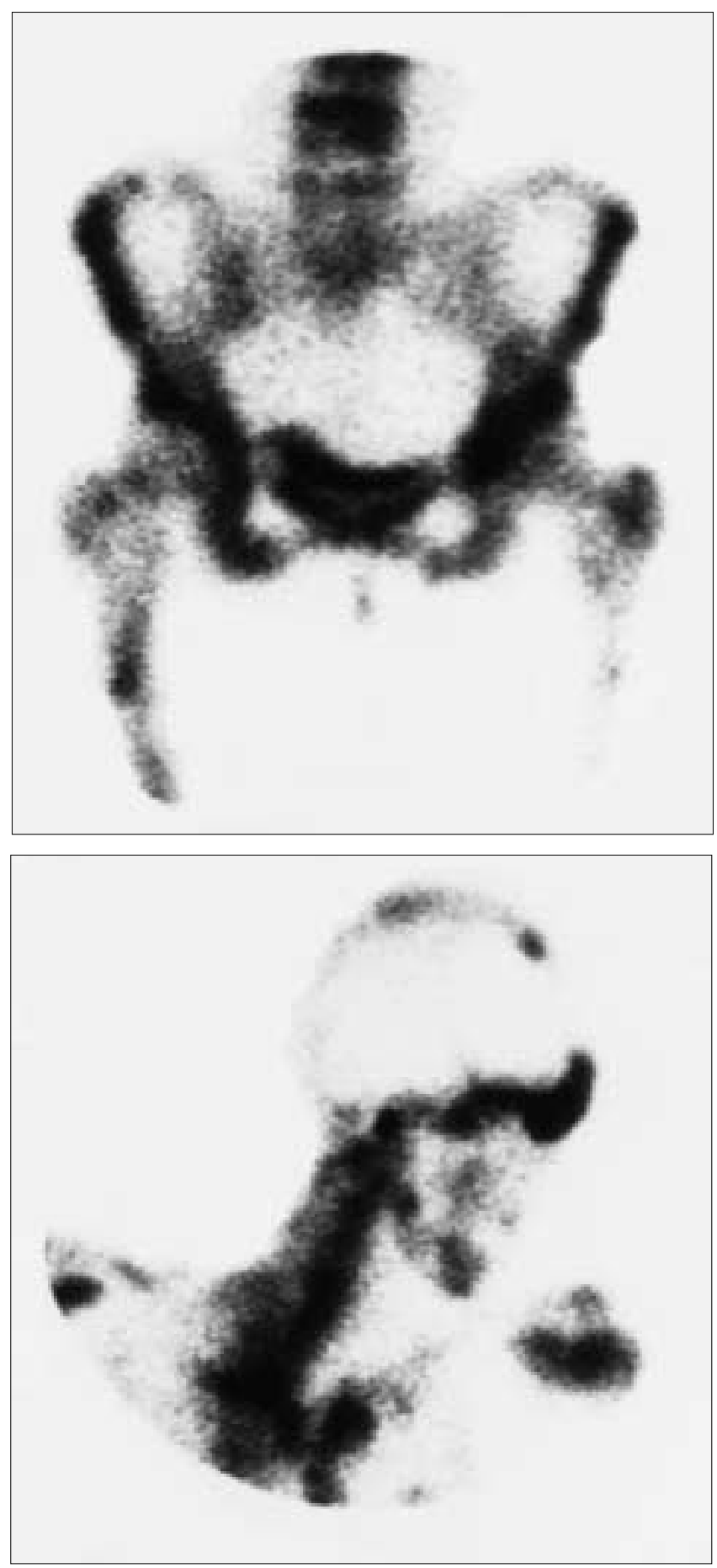
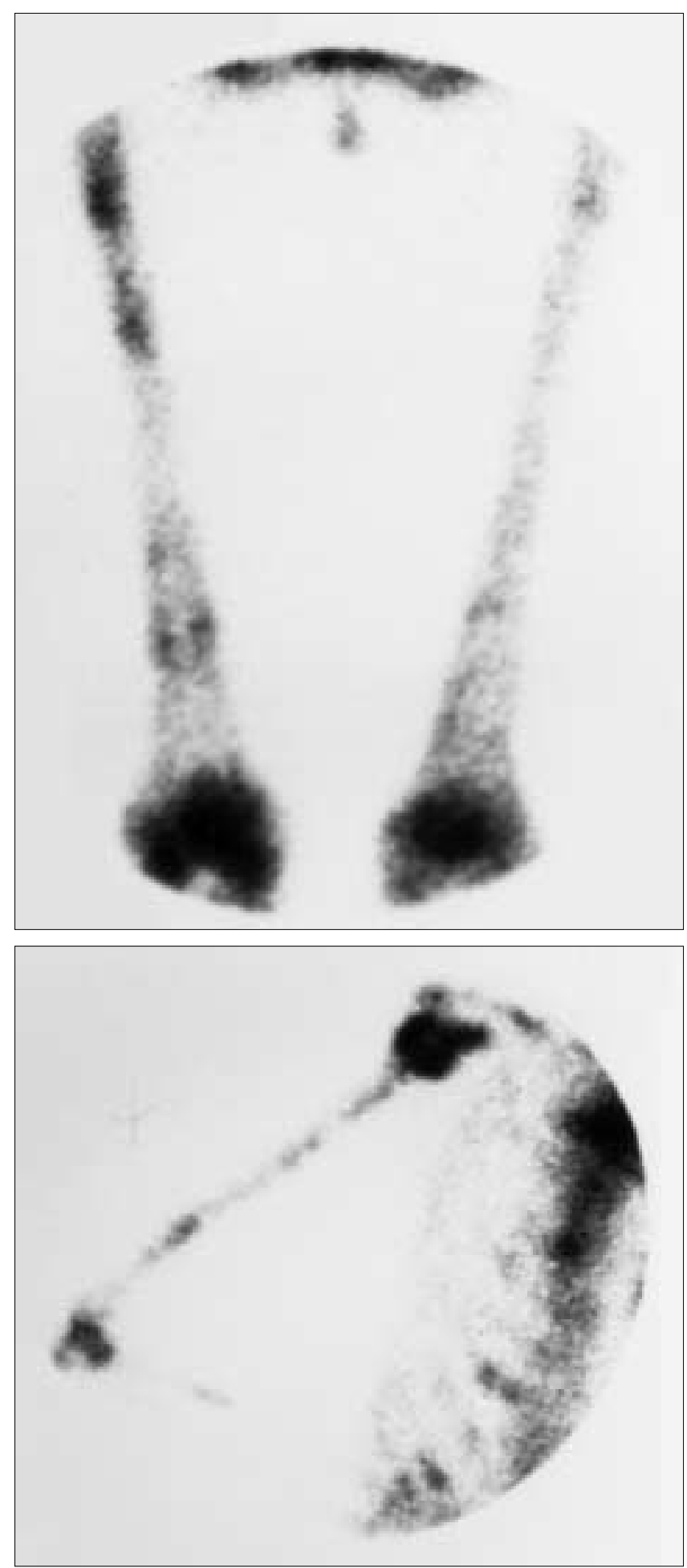

Figure 2) Technetium bone scan showing widespread metastatic basal cell carcinoma. Note areas of abnormal uptake in the Top left pelvis, Bottom left neck and skull, Top right femurs bilaterally and Bottom right right humerous

a chest $\mathrm{X}$-ray showed right upper lobe pneumonia, and CT scan showed a possible right frontal lobe recurrence. Technetium bone scan was indicative of central and right frontal lobe recurrence, but it was not possible to determine whether this was due to mechanical irritation, osteomyelitis or tumour recurrence. There were also areas of increased uptake in the right acetabular region, and the 12 th and 10th thoracic verte- brae. A craniectomy was performed to remove the infected plate, and the pathology report showed the overlying skin to be positive for BCC.

After further resection and antibiotic treatment, the defect was reconstructed using a free latissimus dorsi muscle flap with split-thickness skin grafting.

The patient was again followed in a clinic without signifi- 


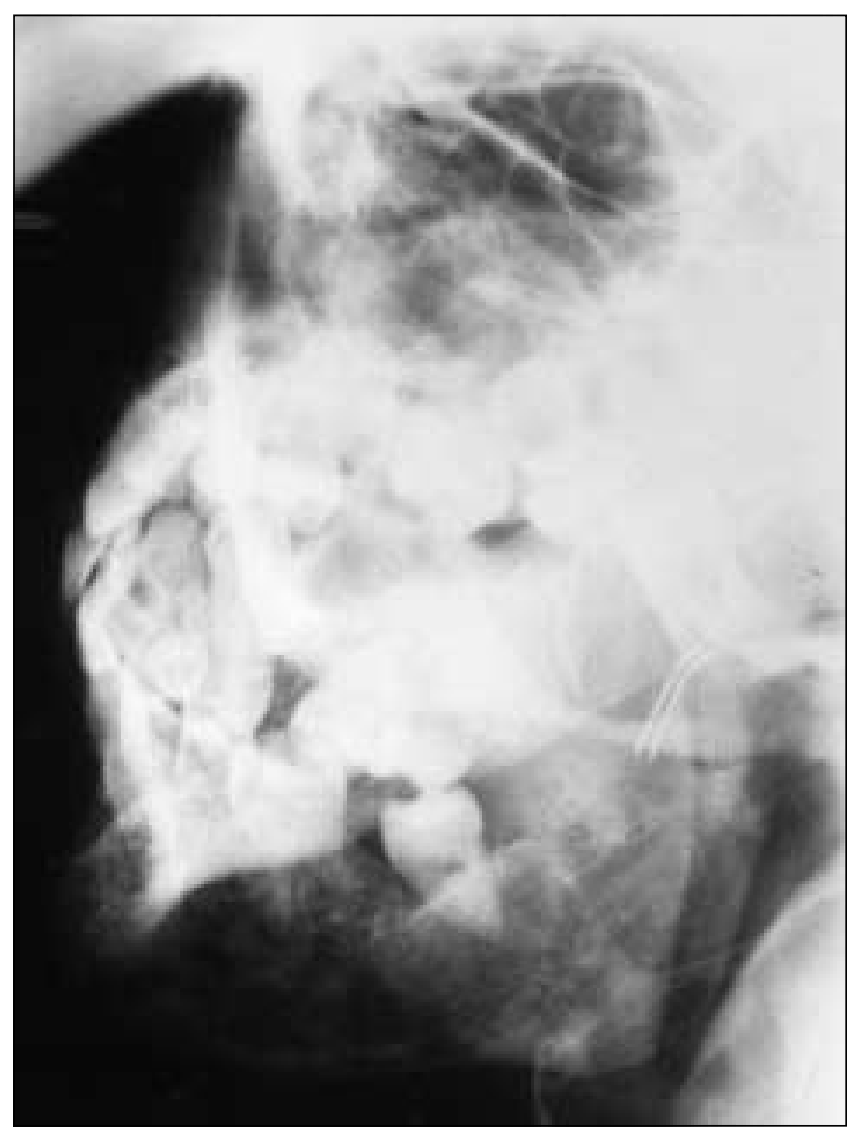

Figure 3) X-ray of mandible showing metastatic basal cell carcinoma. Only a washed out outline of the mandible remains visible

cant development until April 1995. Her right eye was then noted to be proptotic, and vision in the same eye was lost. There was a large ulcer extending from the edge of her frontal skin flap down over her forehead. Subcutaneous nodules were palpated on both sides of the nose and over the sternum between the breasts. X-ray revealed a mottled appearance in the anterior superior iliac crests bilaterally, the inferior pubic rami, both supra-acetabular regions, both femurs, the left proximal radius and the right distal humerus (Figure 1). CT scan showed left frontal sinus destruction with erosion into the left orbit. Technetium bone scan showed increased areas of uptake in the spine, ribs, pelvis, sternum, both femurs, proximal tibias, both humeri, and distal radii and ulnae bilaterally (Figure 2). The pathology report showed the subcutaneous nodule over the sternum between the breasts to be $\mathrm{BCC}$ with a histological appearance similar to the original tumour and no squamous component, thus meeting the criteria for MBCC.

In May 1995, she was admitted for elective intramedullary nailing of both femurs due to impending fracture. X-ray revealed lytic lesions throughout the mandible, distal clavicles, proximal humeri and $\mathrm{C} 1$ vertebrae (Figure 3). Her femurs were nailed bilaterally, and bone reamings were positive for BCC. She received $800 \mathrm{cGy}$ in one fraction to each femur and $1200 \mathrm{cGy}$ in three fractions to her right and left lateral cervical spine.
The patient subsequently received palliative chemotherapy in the form of 10 courses of toposide $150 \mathrm{mg}$, and antineoplastic $30 \mathrm{mg}$ over a 12 -month period. Following one year of chemotherapy, the patient was seen for difficulty opening her mouth with an associated $13.62 \mathrm{~kg}$ weight loss, and persistent proptosis and pain in her right eye. CT scan at that time revealed numerous bony metastases throughout her skull base and into her right orbit. She received further palliative treatment in the form of $1500 \mathrm{cGy}$ to the right eye, and $2000 \mathrm{cGy}$ in total to each of the left and right temporomandibular joints.

The patient succumbed to her disease on August 22, 1996 - approximately 12 years after the lesion was first noted by the patient, five years after her initial presentation for treatment and 16 months after metastatic disease was confirmed.

\section{DISCUSSION}

MBCC typically occurs in middle-aged (mean approximately 48 years of age) men (twice as many men as women) with recurrent disease that is refractory to multiple treatments. The typical initial tumour begins on the face $(67 \%)$ and is large, neglected, ulcerating and locally invasive $(8-10)$. The present case reported is somewhat unusual in that the tumour began in a 21-year-old woman and ultimately showed extremely widespread metastases. The primary lesion itself was quite typical of those leading to MBCC with respect to size, location and invasive tendencies.

The route of metastasis for BCC may be both lymphatic and hematogenous. The most common sites are local lymph nodes (65\%), lungs (34\%) and bone (19\%) (9). Metastases are usually limited to one site (70\%) and rarely occur in multiple sites (30\%) (10). Such dramatic and widespread metastases, as seen in the present case, are indeed quite rare.

There has been some discussion in the literature regarding the effect of the site of the primary tumour on subsequent recurrence and ultimate metastasis. It has been shown that tumours of the face, scalp and ears are more likely to recur and subsequently metastasize. This observation may be explained by attempts at more conservative surgery in these areas leading to incomplete surgical excision. However, there is more agreement that tumours in these areas have an increased tendency to metastasize due to the thin skin and increased concentration of large calibre vessels in the area $(9,11)$. Despite numerous reviews, it is unclear whether tumours are more likely to recur and subsequently metastasize because of their innate characteristics or because of unsuccessful treatment.

In accordance with the slow growth of BCC, the mean duration from primary development to metastasis is approximately 10 to 12 years $(7,10,12)$. However, after documented metastasis, the survival time is surprisingly short, with reports ranging from eight to 10 months $(8,12-14)$. The present case fits with previous reports in that metastasis was identified approximately 12 years after the initial lesion was detected by the patient. Survival after metastasis, however, was somewhat longer at 16 months. 


\section{CONCLUSIONS}

The present case meets the criteria for an MBCC. It is unusual in that the patient was female and young, and that the tumour metastasized diffusely throughout her body. The primary tumour was typical of MBCC because it was located on the scalp, $7 \mathrm{~cm}$ in diameter, ulcerating, neglected and refractory to treatment.

\section{REFERENCES}

1. Silverberg E, Lubera JA. Cancer Stats 1989;39:3.

2. Shanoff LB, Spira M, Hardy SB. Basal cell carcinoma: A statistical approach to rational management. Plast Reconstr Surg 1967;39:619.

3. Lo JS, Snow SN, Reizner GT, Mohs FE, Larson PO, Hruza GJ. Metastatic basal cell carcinoma: report of twelve cases with a review of the literature. J Am Acad Dermatol 1991;24:715-9.

4. Lattes R, Kessler RW. Metastasizing basal cell epithelioma of the skin. Cancer 1951;4:866-78

5. Paver K, Poyzer K, Burry N, Deakin M. The incidence of basal cell carcinoma and their metastases in Australia and New Zealand. Aust J Dermatol 1973; 14:53-6.

6. Cotran RS. Metastasizing basal cell carcinomas. Cancer 1961;14:1036-40.

7. Mikhail GR, Nims LP, Kelly AP, Ditmars DM, Eyler WR. Metastatic basal cell carcinoma: review, pathogenesis, and report of two cases. Arch Dermatol 1977;113:1261-9.

8. von Domarus H, Stevens PJ. Metastatic basal cell carcinoma. J Am Acad Dermatol 1984;10:1043-60.

9. Snow SN, Sahl W, Lo JS, et al. Metastatic basal cell carcinoma: report of five cases. Cancer 1994;73:328-35.

10. Amonette RA, Salasche SJ, Chesney TM, Clarendon CC, Dilawari RA. Metastatic basal-cell carcinoma. J Dermatol Surg Oncol 1981;7:397-400.

11. Dzubow LM. Metastatic basal cell carcinoma originating in the supra-parotid gland. J Dermatol Surg Oncol 1986;12:1306-8.

12. Farmer ER, Helwig EB. Metastatic basal cell carcinoma: A clinical pathologic study of seventeen cases. Cancer 1980;46:748-57.

13. Conway H, Hugo NE. Metastatic basal cell carcinoma. Am J Surg 1965;110:620-4

14. Kord JP, Cottel WI, Proper S. Metastatic basal cell carcinoma. J Dermatol Surg Oncol 1982;8:604-8. 